\title{
Assessment of Serum Lipid Profile among Male Cigarette Smokers in Jos Metropolis
}

\author{
Olaniru $\mathrm{OB}^{1}$, Ochalefu $\mathrm{DO}^{2}$, Obeta $\mathrm{MU}^{3 *}$, Ibanga $\mathrm{IE}^{3}$, Fiyaktu $\mathrm{YB}^{1}$, Jwanse $\mathrm{RI}^{4}$ and Orelaja $\mathrm{HA}^{1}$ \\ ${ }^{1}$ Department of Chemical Pathology, Jos University Teaching Hospital, Nigeria \\ ${ }^{2}$ Department of Medical Biochemistry, Benue State University, Nigeria \\ ${ }^{3}$ Department of Chemical Pathology, Federal School of Medical Laboratory Science, Jos Nigeria \\ ${ }^{4}$ Health and Development Support Programme (HANDS), Nigeria
}

*Corresponding author: Obeta MU, Department of Chemical Pathology, Federal School of Medical Laboratory Science, Jos Nigeria Nigeria.

To Cite This Article: Obeta MU. Assessment of Serum Lipid Profile among Male Cigarette Smokers in Jos Metropolis. Am J Biomed Sci \& Res. 2019 - 3(6). AJBSR.MS.ID.000732. DOI: 10.34297/AJBSR.2019.03.000732

Received: July 01, 2019 | Published: July 10, 2019

\begin{abstract}
Background: Cigarette smoking is one of the habits that affects health but there is increase in number of people adapting to the habit day after day globally and in Jos-Nigeria.
\end{abstract}

Aim of study: The study is aimed at finding out the effect of smoking on lipid profiles between smokers and non-smokers so as to provide information for use to educate and advice smokers appropriately on the dangers of smoking.

Study volunteers and methods: A cross sectional comparative study was performed in Jos metropolis to evaluate the change in the serum lipid profile in healthy male smokers and non-smokers subject between the ages of 15-45years. A total of 100 volunteers were selected and grouped as non-smokers (control) and smokers. All subjects were issued with questionnaire to get the vital data of the subjects. Biochemical analysis of fasting serum lipid profile of each group was assessed by enzymatic methods with aid of spectrophotometer.

Result: The results obtained in the research showed that smokers have the mean and standard deviation of total cholesterol, (TC), triglyceride (TG),high density lipoprotein-cholesterol (HDL-C) and low density lipoprotein-cholesterol (LDL-C) as $6.40 \pm 1.41 \mathrm{mMol} / \mathrm{L}, 1.90 \pm 0.66 \mathrm{mMol} / \mathrm{L}$ $1.80 \pm 0.52 \mathrm{mMol} / \mathrm{L}$ and $3.6 \pm 1.21 \mathrm{mMol} / \mathrm{L}$ respectively whereas non-smokers have the mean and standard deviation of total cholesterol,(TC), triglyceride (TG),high density lipoprotein-cholesterol (HDL-C) and low density lipoprotein-cholesterol (LDL-C) as $3.20 \pm 0.71 \mathrm{mMol} / \mathrm{L}, 1.30 \pm 0.40$ $\mathrm{mMol} / \mathrm{L}, 2.0 \pm 0.20 \mathrm{mMol} / \mathrm{L}$ and $1.30 \pm 0.80 \mathrm{mMol} / \mathrm{L}$ respectively.

Conclusion: The TC, TG and LDL-C of smokers were greater than those of non-smokers, showing a significance at P<0.05 but the HDL-C of smokers were less than that of non-smokers. Cigarette smoking induces alterations in serum lipid levels in direction that increases the risk of coronary heart disease. The youths should be educated on the health implications of cigarette smoking for a healthy society and environment.

Keywords: Lipid profile; Cigarette Smokers; Jos

\section{Introduction}

Smoking is now acknowledged to be one of the leading causes of preventable morbidity and is one of the largest single preventable causes of ill health in the world. Smoking as an environmental factor can alter normal lipid profile and cause heart diseases [1,2]. Nearly every cigarette smoker begins as a teenager. The average smoker tries their first cigarette at the age of 12 [3] and may be a regular smoker by the age of 14 years [4]. Smokers always crave for more cigarettes most especially after an overnight abstinence due to the effect of Nicotine, acetylcholine, and dopamine on Central Nervous System (CNS), which causes addictiveness. On average, smoking increases the risk of cardiovascular heart disease by $70 \%$ when compared with nonsmoking. The start of even modest cigarette smoking during adolescence and early adulthood alters the serum lipid and lipoproteins levels $[5,6]$. Smokers have high risk for coronary artery disease (CAD) compared to non-smokers, partly attributed to some altered physiological factors including altered coagulation state, damages vascular walls, and an alteration in lipid and lipoprotein content [6].Davis [7] described various mechanisms leading to lipids alteration by smokers to include:

a) Stimulation sympathetic adrenal system by Nicotine leading to increase secretion of catecholamine resulting in 
increased lipolysis and increased concentration of plasma free fatty acids (PFFA) which further result in increased secretion of hepatic free fatty acids (HFFA) and hepatic triglycerides,

b) Fall in estrogen level which occurs due to smoking that further leads to decreased HDL-cholesterol,

c) Presence of hyperinsulinaemia in smokers leading to increased cholesterol, LDL-Cholesterol, VLDL- cholesterol and triglycerides due to decreased activity of lipoprotein lipase.

Research has shown a correlation between the number of cigarettes smoked and cardiovascular morbidity and mortality. Cigarette smoking leads to increase in the concentration of serum total cholesterol, triglycerides, LDL-cholesterol, VLDL-cholesterol and fall in the levels of anti-atherogenic HDL- cholesterol. The smoke described as plaque sticks to the inside walls of the vessels causing the vessels to narrow and the Platelets get trapped in the plaque, causing further narrowing and blood clotting. When the artery is completely occluded, the part of the heart muscle supplied by that coronary artery can be cut entirely from blood supply, causing heart attack. Inhaling cigarette smoke also leads to an increased free radicals in the body which can cause damages to the body in a large amount to cells and tissues, and could also triggered an immune response $[2,8,9,10]$. Smoking in different form is a major risk factor for atherosclerosis and coronary Heart Disease (CHD) due to the chemical components of cigarette which provides for research interest to check the effect of smoking on lipid profile in Jos Metropolis which hosts several higher institutions in the State.

\section{Methods}

A total of 100 apparently health males subjects within the ages of 15-45years were used in this study, made up of 80 smokers and
20 non-smokers as the control. All the subjects reside within Jos Metropolis. The subjects were selected through self-administered questionnaire containing series of question for proper screening and selection of suitable subjects. The lipid profile was determined using the methodology as described by Ochei \& Kolhaktar [11]. Statistical Analysis employed was Mean, Standard Deviation and Students t-test Ethical Consideration was duly followed ranging from the volunteers giving consent of participation and obtaining ethical committee approval from Federal School of Medical Laboratory Technology, Jos before the research was carried out.

\section{Result}

A total of 100 fasting samples; 80 smokers and 20 non-smokers were estimated (essayed) for total cholesterol (TC), high-density lipoprotein-cholesterol (HDL-C), Triglycerides (TG) and Lowdensity lipoproteins cholesterol (LDL-C) using respective methods. All data were expressed as Mean \pm Standard Deviation $(\mathrm{X} \pm \mathrm{SD}$ ) for control (non-smokers), and smokers with varying numbers of cigarettes per day as shown below in table 1 and 2 and the statistical significance was evaluated by student $t$-test at confident interval of 95\%. The smokers mean and standard deviation of Total cholesterol (TC), Triglyceride (TG), High density lipoproteincholesterol (HDL-C) and Low density lipoprotein-cholesterol (LDL-C) were $6.40 \pm 1.41,1.90 \pm 0.66,1.80 \pm 0.52$ and $3.60 \pm 1.21$ $\mathrm{mMol} / \mathrm{L}$ respectively whereas non-smokers' mean and standard deviation of Total cholesterol, (TC), Triglyceride (TG), High density lipoprotein-cholesterol (HDL-C) and Low density lipoproteincholesterol (LDL-C) were $3.20 \pm 0.71,1.30 \pm 0.40,2.00 \pm 0.20$ and $1.30 \pm 0.80 \mathrm{mMol} / \mathrm{L}$, greater than those of non-smokers, showing a significant value at $\mathrm{P}<0.05$ but the HDL-C of smokers were less than that of non-smokers.

Table 1: The mean and standard deviation $(\mathrm{X} \pm \mathrm{SD})$ of Non-smokers and smokers.

\begin{tabular}{|c|c|c|c|c|c|c|}
\hline \multirow{2}{*}{ Parameters } & Control & Smokers & C- Value & T- Value & P-value & Remark \\
\hline TC (mMo1/L) & $3.20 \pm 0.71$ & $6.4 \pm 1.41$ & 4.47 & 1.98 & P $<0.05$ & Significant \\
\hline HDL-C (mMo1/L) & $2.00 \pm 0.20$ & $1.80 \pm 0.52$ & 8.87 & 1.98 & P<0.05 & Significant \\
\hline TG (mMo1/L) & $1.30 \pm 0.40$ & $1.90 \pm 0.66$ & 4.45 & 1.98 & P<0.05 & Significant \\
\hline LDL-C (mMo1/L) & $1.30 \pm 0.80$ & $3.60 \pm 1.21$ & 8.95 & 1.98 & P<0.05 & Significant \\
\hline
\end{tabular}

Note: NB: Calculated Value is greater than tabulated value showing significance at $\mathrm{P}<0.05$.

Key: C: Calculated value; T: Tabulated value.

Table 2: The mean and standard deviation $(X \pm S D)$ of control (non-smokers) and smokers of 1-10 cigarettes per day and smokers of 11-20 cigarettes per day subjects.

\begin{tabular}{|c|c|c|c|c|c|c|c|}
\hline Parameters & $\begin{array}{l}\text { Control } \\
\mathbf{n}=\mathbf{2 0}\end{array}$ & $\begin{array}{l}\text { Smokers } \\
\begin{array}{l}1-20 \\
\mathrm{n}=30\end{array}\end{array}$ & $\begin{array}{l}\text { Smoker } \\
\begin{array}{c}\text { 11-20 } \\
n=50\end{array}\end{array}$ & C-Value & T-Value & P-value & Remark \\
\hline $\mathrm{TC}(\mathrm{mMo} 1 / \mathrm{L})$ & $3.20 \pm 0.71$ & $5.00 \pm 1.21$ & $7.00 \pm 1.21$ & 4.47 & 1.98 & $\mathrm{P}<0.05$ & Significant \\
\hline HDL-C (mMo1/L) & $2.00 \pm 0.20$ & $1.80 \pm 0.14$ & $1.90 \pm 0.57$ & 8.87 & 1.98 & $\mathrm{P}<0.05$ & Significant \\
\hline $\mathrm{TG}(\mathrm{mMo} 1 / \mathrm{L})$ & $1.30 \pm 0.40$ & $1.50 \pm 0.11$ & $2.10 \pm 0.61$ & 4.45 & 1.98 & $\mathrm{P}<0.05$ & Significant \\
\hline LDL-C (mMo1/L) & $1.30 \pm 0.80$ & $4.10 \pm 1.04$ & $4.10 \pm 1.04$ & 8.95 & 1.98 & $\mathrm{P}<0.05$ & Significant \\
\hline
\end{tabular}




\section{Discussion}

In this study, the serum total cholesterol levels in smokers as compared to that of controls. The cholesterol concentration increases with increase in number of cigarettes smoked as shown in this study. It has been reported that incidence of coronary Heart Disease (CHD) is directly related to number of cigarettes smoked and smoking more than 10 cigarettes regularly constitutes a major risk factor for Ischemic Heart Disease (ISHD) by Vasudevan \& Sreekumari [12]. Similarly, higher levels of triglycerides (TG) were found in smokers as compared to controls Some studies have suggested that triglyceride levels are the most important factors leading to coronary heart disease (CHD), although in fact, triglycerides as a risk factor has been suggested by various research workers [13]. The values of serum triglycerides were significantly higher in subjects smoking 11-20 cigarettes per day as compared to those smoking 1-10 cigarettes per day [2]. HDL serum level showed decrease in smokers as compared to controls. The results are in conformity with Zamir et al. [13] who observed that levels of HDL in smokers as the result of threat of developing atherosclerosis and Coronary Heart Disease (CHD) could be increased. The level of HDL in those smoking 11-20 cigarettes per day showed no significant difference statistically with those smoking 1-10 cigarettes per day. On the other hand, the level of serum LDL-Cholesterol levels are significantly increased in smokers as compared with the control. It has been described that nicotine contained cigarettes increased the circulating pool of atherogenic LDL through accelerated transfers of lipid from HDL and impaired clearance of IDL from plasma compartment and hence LDL Cholesterol in the arterial wall increased. LDL values were significantly higher in those smoking 10-20 cigarettes per day as compared to those smoking 10-10 per day. This study is in agreement with the earlier works $[1,5,8,9,12,13]$.

\section{Conclusion}

From the results of this study, the serum anti-atherogenic HDL- Cholesterol level is significantly low in smokers irrespective of the number of cigarettes they smoked. The serum level of total cholesterol, LDL-cholesterol and triglycerides (TG) are significantly increased in smokers as compared to non-smokers, and in those smoking 11-20 cigarettes per day as compared to those smoking 1-10 cigarettes per day and therefore raising the cardiovascular disease risk. From this study, it is good to recommend to all smokers and intending smokers in Jos Metropolis and the world at large that:

a) Smoking should be avoided as much as possible by smokers and intending smokers for the benefit of cardiac health.

b) Young people should be continually educated on the dangers of smoking in order not to take up smoking. c) Legislative laws should be enacted prohibiting people from smoking in public places like cinema halls, studio, inside vehicles, institutions of learning especially secondary schools and higher institutions of learning in Jos Plateau State by the State House of Assembly.

d) Tobacco companies should be taxed heavily to discourage production and distribution in Jos-Nigeria.

e) There should be prohibition of advertisement or any form of cigarette on the mass media.

f) Health workers should discourage their patients from smoking as a take home message after visiting any health facility in Jos.

\section{References}

1. Elhashimi EH, Haala MG, Zakya AA, AE Ali (2013) Effect of Cigarette Smoking on Lipid Profile In Male at Collage of Police and Low Khartoum, Sudan. Asian Journal of Biomedical and Pharmaceutical Sciences 03(26): 28-31.

2. Neki NS (2002) Lipid Profile in chronic smokers. Journal of Indian Academy of clinical medicine 3(1).

3. DiFranza JR, Eddy JJ, Brown LF, Riyanzi JL, B Ann (1994) Tobacco acquisition and cigarette brand selection among youth. Tob Control 3(4): 334-338.

4. Hogan A, McLellan L, A Bauman (2000) Health promotion needs of young people with disabilities, a population study. Disabil Rehabil 22(8): 352-357.

5. Ram BJ, D Alan (2018) Associations between smoking and lipid/ lipoprotein concentrations among US adults aged $\geq 20$ years. J Circ Biomark 7: 1-10.

6. Afrin L, Sultan FS, Ahmed A, MR Amin (2006) Evaluation of serum triglyceride and total-cholesterol status in adolescent smokers. J Bangladesh Soc Physol l: 14-18.

7. Davis PM (2003) Addicted to the leaf, Tobacco control 12: 91-93.

8. Devaranavadgi BB, Aski BS, Kashinath RT, IA Hundekari (2012) Effect of Cigarette Smoking on Blood Lipids -A Study in Belgaum, Northern Karnataka, India. Global Journal of Medical Research.

9. Afira W (2010) Effects of Smoking on Lipid Profile of Teenage Male Population in Lahore City. International Journal of medicine and medical science 2(6): 172.

10. Wheeler DC, DB Bernard (1994) Lipid abnormalities in the nephrite syndrome: causes, Consequences and treatment. Am J Kidney Dis 23: 331-332.

11. Ochei J, A Kolhaktar (2000) Medical Laboratory science. Theory and Practical ( $6^{\text {th }}$ edn), Tata Mc. Graw- Hill Publishing Company.

12. Vasudevan DM, S Sreekumari (2007) Jaypee Biochemistry textbook $5^{\text {th }}$ Edn, pp: 149-150.

13. Zamir MAA, Mohammed SB, S Mohammed (2000) Lipid profile in smoking JAMC 12(13): 19-21. 